\title{
Gastric adenomas and their management in familial adenomatous polyposis
}

\section{(ㄷ)(1) $\odot$}

\section{Authors}

Isabel Martin ${ }^{1,2}$, Victorine H. Roos ${ }^{3}$, Chukwuemeka Anele ${ }^{1,2}$, Sarah-Jane Walton ${ }^{4}$, Victoria Cuthill ${ }^{1}$, Noriko Suzuki ${ }^{1}$, Barbara A. Bastiaansen ${ }^{3}$, Susan K. Clark ${ }^{1,2}$, Alexander von Roon ${ }^{5}$, Evelien Dekker ${ }^{3}$, Andrew Latchford ${ }^{1,2}$

Institutions

1 The Polyposis Registry, St. Mark's Hospital, London, United Kingdom

2 Department of Surgery and Cancer, Imperial College London, United Kingdom

3 Department of Gastroenterology and Hepatology, Amsterdam UMC, University of Amsterdam, Cancer Center Amsterdam, Netherlands

4 Department of Surgery, Basildon and Thurrock University Hospital, Basildon, United Kingdom

5 Department of Surgery, University College Hospital, London, United Kingdom

submitted 21.2.2020

accepted after revision 17.9.2020

published online 17.9.2020

\section{Bibliography}

Endoscopy 2021; 53: 795-801

DOI 10.1055/a-1265-2716

ISSN 0013-726X

(c) 2021. The Author(s). This is an open access article published by Thieme under the terms of the Creative Commons Attribution-NonDerivative-NonCommercial License, permitting copying and reproduction so long as the original work is given appropriate credit. Contents may not be used for commercial purposes, or adapted, remixed, transformed or built upon. (https://creativecommons.org/ licenses/by-nc-nd/4.0/) Georg Thieme Verlag KG, Rüdigerstraße 14, 70469 Stuttgart, Germany

Supplementary material Supplementary material is available under https://doi.org/10.1055/a-1265-2716

\section{Scan this QR-Code for the author commentary.}

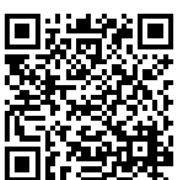

Corresponding author

Isabel Martin, Polyposis Registry, St. Mark's Hospital and Academic Institute, Watford Road, Harrow HA1 3U],

United Kingdom

isabel.martin1@nhs.net

\section{ABSTRACT}

Background Patients with familial adenomatous polyposis (FAP) are at increased risk of developing gastric adenomas. There is limited understanding of their clinical course and no consensus on management. We reviewed the management of gastric adenomas in patients with FAP from two centers.

Methods Patients with FAP and histologically confirmed gastric adenomas were identified between 1997 and 2018. Patient demographics, adenoma characteristics, and management/surveillance outcomes were collected.

Results Of 726 patients with FAP, 104 (14\%; 49 female) were diagnosed with gastric adenomas at a median age of 47 years (range 19-80). The median size of gastric adenomas was $6 \mathrm{~mm}$ (range 1.5-50); 64 (62\%) patients had adenomas located distally to the incisura. Five patients (5\%) had gastric adenomas demonstrating high-grade dysplasia (HGD) on initial diagnosis, distributed equally within the stomach. The risk of HGD was associated with adenoma size $(P=0.04)$. Of adenomas $>20 \mathrm{~mm}, 33 \%$ contained HGD. Two patients had gastric cancer at initial gastric adenoma diagnosis. A total of 63 patients (61\%) underwent endoscopic therapy for gastric adenomas. Complications occurred in three patients $(5 \%)$ and two $(3 \%)$ had recurrence, all following piecemeal resection of large $(30-50 \mathrm{~mm})$ lesions. Three patients were diagnosed with gastric cancer at median follow-up of 66 months (range $66-115$ ) after initial diagnosis.

Conclusions We observed gastric adenomas in $14 \%$ of patients with FAP. Of these, $5 \%$ contained HGD; risk of HGD correlated with adenoma size. Endoscopic resection was feasible, with few complications and low recurrence rates, but did not completely eliminate the cancer risk. 

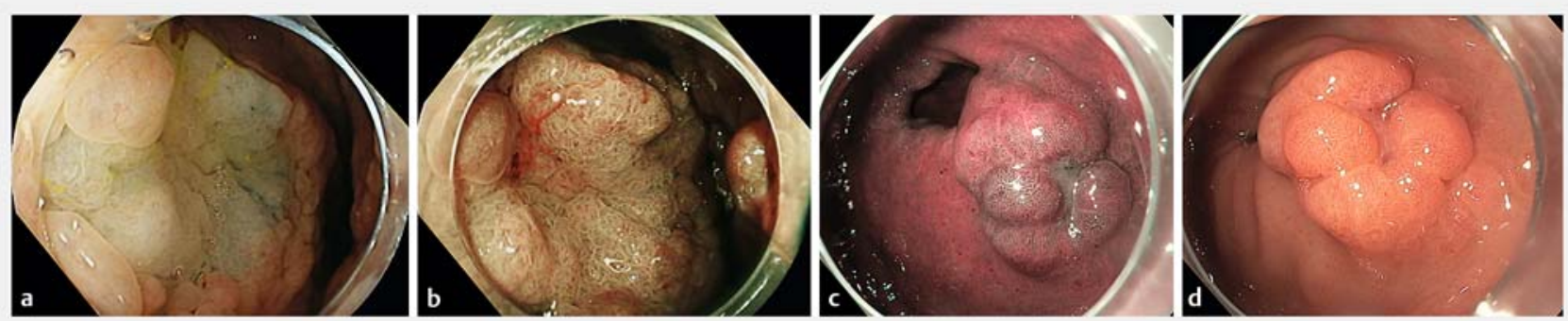

- Fig. 1 Endoscopic appearances of gastric adenomas. a Proximal adenoma (high definition image with white light). b Proximal adenoma (high definition image with flexible spectral imaging color enhancement). c Distal antral adenoma (white-light imaging). d Distal antral adenoma (high definition images with narrow-band imaging).

\section{Introduction}

Familial adenomatous polyposis (FAP) is a rare autosomal dominant inherited cancer-susceptibility syndrome caused by constitutional pathogenic variant in the APC gene [1]. Patients have an almost $100 \%$ risk of colorectal cancer by the age of 40 in the absence of prophylactic colectomy [2]. With screening and surveillance, mortality from colorectal cancer has improved, and long-term survival is increasingly determined by extracolonic manifestations including duodenal cancer and desmoid disease [3-5].

Gastric adenomas and cancer are increasingly recognized as a clinical problem in FAP [6-8]. Historical data are difficult to interpret, but it has been suggested that in Western countries there is no increased risk of gastric cancer in patients with FAP [9]. This conflicts with data from Korea and Japan, where an increased risk of gastric cancer has been demonstrated in patients with FAP, over and above the higher background gastric cancer rates in those countries [10-12]. Furthermore, data from those countries have also suggested a much higher incidence of gastric adenomas in FAP than has been observed in the West.

Identifying lesions with neoplastic potential is challenging [13-16]. A recent series describing gastric cancer in FAP in Western countries has highlighted that gastric cancer is more likely to be proximal and associated with carpeting fundic gland polyposis, which makes identification of premalignant gastric adenomas difficult [6-8]. In addition, the prognosis was poor, with many having advanced disease at the time of diagnosis, again perhaps highlighting the difficulty in identifying and managing the benign precursor adenoma.

Gastric adenomas in patients with FAP are considered to be premalignant lesions, with studies showing that up to $14 \%$ contain high-grade dysplasia (HGD) [6, 17]. However, although the removal of suspicious gastric lesions might prevent progression to adenocarcinoma, specific guidance on the management and surveillance of gastric lesions in patients with FAP is lacking [13]. We aimed to describe the prevalence, characteristics, and our experience on the management of gastric adenomas in patients with FAP, combining data from two European polyposis registries.

\section{Methods}

We performed a retrospective review of all patients with FAP and histologically confirmed gastric adenomas diagnosed between March 1997 and May 2018, which were identified from prospectively maintained polyposis registries at St. Mark's Hospital, London, and the Amsterdam UMC, Academic Medical Center. The work was approved by the research department from each institution.

All patients with a histological diagnosis of gastric adenoma were included. All patients with FAP aged over 25 years underwent upper gastrointestinal screening endoscopy with surveillance intervals determined by Spigelman Classification Score, which assesses the severity of duodenal disease based on clinical and pathological features. These endoscopies were performed using white-light endoscopy and, if available and needed, virtual chromoendoscopy was used for lesion characterization ( $\bullet$ Fig. $\mathbf{1}$ ). There was no standardized surveillance protocol in place for the treatment or follow-up of gastric adenomas.

Patients' medical notes, and endoscopy and pathology reports were obtained and reviewed. Patient demographics, APC mutation (including clinical diagnoses of FAP without an identified mutation), adenoma location, histology, intervention, and follow-up outcomes up to June 2020 were collected. Gastric adenomas were classified as proximal (incisura, body fundus, and cardia) or distal (antrum and pylorus). Recurrence was defined as adenomas reoccurring at the same site or scar.

Fisher's exact test was applied to assess the statistical significance of adenoma size and categorical variables and HGD.

\section{Results}

In total, 726 patients with FAP were identified from hospital databases, of whom 104 (14\%) were diagnosed with a gastric adenoma (see Fig. $1 \mathrm{~s}$ in the online-only supplementary material). A total of 49 patients ( $47 \%$ ) were female and the median age at diagnosis of gastric adenoma was 47 years (range 19-80 years), with a median follow-up of 37 months (range $0-242$ months) (Table $1 \mathrm{~s}$ ). The median size of gastric adenoma was 6 $\mathrm{mm}$ (range $1.5-50 \mathrm{~mm})$, and the majority $(\mathrm{n}=64 ; 62 \%)$ were located distal to the incisura. Fundic gland polyps were present at initial diagnosis of gastric adenoma in $83 \%$ of patients. Heli- 
Table 1 Main features of gastric adenomas demonstrating high and low grade dysplasia.

\begin{tabular}{|c|c|c|c|c|c|}
\hline & $<5 \mathrm{~mm}$ & $5-20 \mathrm{~mm}$ & $>20 \mathrm{~mm}$ & Not classified & Total ${ }^{1}$ \\
\hline \multicolumn{6}{|l|}{ HGD (resected) } \\
\hline Total & 0 & 2 & 2 & 1 & 5 \\
\hline Median age at diagnosis, years & 0 & 43 & 51 & 73 & - \\
\hline \multicolumn{6}{|l|}{ Sex } \\
\hline - Female & 0 & 1 & 1 & 1 & 3 \\
\hline - Male & 0 & 1 & 1 & 0 & 2 \\
\hline \multicolumn{6}{|l|}{ Location relative to incisura } \\
\hline - Proximal & 0 & 1 & 2 & 0 & 3 \\
\hline - Distal & 0 & 1 & 0 & 1 & 2 \\
\hline \multicolumn{6}{|l|}{ Multiplicity } \\
\hline - Solitary & 0 & 1 & 2 & 1 & 4 \\
\hline - Multiple & 0 & 1 & 0 & 0 & 1 \\
\hline \multicolumn{6}{|l|}{ Intervention } \\
\hline - Cold biopsy & 0 & 1 & 0 & 0 & 1 \\
\hline - EMR & 0 & 1 & 2 & 0 & 3 \\
\hline - ESD & 0 & 0 & 0 & 1 & 1 \\
\hline Recurrence $^{2}$ & 0 & 0 & 2 & 0 & 2 \\
\hline Complications $^{3}$ & 0 & 0 & 1 & 0 & 1 \\
\hline Deceased $^{4}$ & 0 & 0 & 1 & 0 & 1 \\
\hline \multicolumn{6}{|l|}{ LGD (resected) } \\
\hline Total & 16 & 24 & 3 & 15 & 58 \\
\hline Median age at diagnosis, years & 44 & 46 & 52 & 50 & - \\
\hline \multicolumn{6}{|l|}{ Sex } \\
\hline - Female & 7 & 9 & 2 & 6 & 24 \\
\hline - Male & 9 & 15 & 1 & 9 & 34 \\
\hline \multicolumn{6}{|l|}{ Location relative to incisura } \\
\hline " Proximal & 4 & 11 & 3 & 6 & 24 \\
\hline " Distal & 11 & 11 & 0 & 9 & 31 \\
\hline - Proximal and distal & 1 & 1 & 0 & 0 & 2 \\
\hline - Not classified & 0 & 1 & 0 & 0 & 1 \\
\hline \multicolumn{6}{|l|}{ Multiplicity } \\
\hline - Solitary & 8 & 17 & 0 & 5 & 30 \\
\hline - Multiple & 8 & 7 & 3 & 8 & 26 \\
\hline - Not classified & 0 & 0 & 0 & 1 & 1 \\
\hline \multicolumn{6}{|l|}{ Intervention } \\
\hline - Snare polypectomy & 1 & 6 & 0 & 2 & 9 \\
\hline - EMR & 12 & 15 & 1 & 12 & 40 \\
\hline - ESD & 1 & 2 & 1 & 0 & 4 \\
\hline - Cold biopsy & 1 & 0 & 0 & 0 & 1 \\
\hline
\end{tabular}


- Table 1 (Continuation)

\begin{tabular}{|c|c|c|c|c|c|}
\hline & $<5 \mathrm{~mm}$ & $5-20 \mathrm{~mm}$ & $>20 \mathrm{~mm}$ & Not classified & Total $^{1}$ \\
\hline - ESD and knife-assisted EMR & 0 & 0 & 1 & 0 & 1 \\
\hline - Knife-assisted EMR & 1 & 0 & 0 & 0 & 1 \\
\hline - $\mathrm{APC}$ & 0 & 1 & 0 & 1 & 2 \\
\hline Recurrence & 0 & 0 & 0 & 0 & 0 \\
\hline Complications ${ }^{5}$ & 0 & 2 & 0 & 0 & 2 \\
\hline Deceased $^{6}$ & & 2 & & 1 & 3 \\
\hline \multicolumn{6}{|l|}{ LGD (biopsy only) } \\
\hline Total & 6 & 8 & 1 & 25 & 40 \\
\hline Median age at diagnosis, years & 38 & 38 & 45 & 52 & - \\
\hline \multicolumn{6}{|l|}{ Sex } \\
\hline - Female & 4 & 3 & 0 & 14 & 21 \\
\hline - Male & 2 & 5 & 1 & 11 & 19 \\
\hline \multicolumn{6}{|l|}{ Location } \\
\hline - Proximal & 1 & 2 & 1 & 4 & 8 \\
\hline - Distal & 5 & 6 & 0 & 20 & 31 \\
\hline - Not classified & 0 & 0 & 0 & 1 & 1 \\
\hline \multicolumn{6}{|l|}{ Multiplicity } \\
\hline - Solitary & 3 & 2 & 1 & 12 & 18 \\
\hline - Multiple & 3 & 6 & 0 & 13 & 22 \\
\hline Recurrence $^{7}$ & 0 & 0 & 0 & 0 & 0 \\
\hline \multicolumn{6}{|c|}{ Reasons for no further intervention } \\
\hline \multirow[t]{3}{*}{ - Continue on surveillance } & \multicolumn{3}{|c|}{ Follow-up endoscopy - no evidence of adenoma } & 6 & \multirow[t]{3}{*}{20} \\
\hline & Follow-u & $y$-repeat bio & & 7 & \\
\hline & $\begin{array}{l}\text { Follow-u } \\
\text { ma biop }\end{array}$ & $\begin{array}{l}y \text { - repeat bio } \\
\text { ted }\end{array}$ & ew gastric adeno- & 7 & \\
\hline \multirow[t]{2}{*}{ - Referred for surgery } & \multicolumn{4}{|c|}{ For pancreas-preserving duodenectomy for advanced duodenal disease } & 2 \\
\hline & \multicolumn{4}{|c|}{$\begin{array}{l}\text { For small-bowel transplant for advanced pouch disease having had a previous } \\
\text { pancreas-preserving duodenectomy }\end{array}$} & 1 \\
\hline \multicolumn{5}{|l|}{ Deceased $^{8}$} & 3 \\
\hline \multicolumn{5}{|l|}{ Lost to follow-up } & 14 \\
\hline $\begin{array}{l}\text { EMR, endoscopic mucosal resection } \\
\text { All data are number of patients, exc } \\
{ }^{1} \text { One patient diagnosed with gastri } \\
{ }^{2} \text { One patient proceeded to subtota } \\
\text { EMR/ESD and histology demonstr } \\
{ }^{3} \text { Pain requiring overnight admissio } \\
{ }^{4} \text { Metastatic gastric cancer followin } \\
{ }^{5} \text { Bleeding requiring transfusion and } \\
\text { removal of } 20 \text {-mm distal lesion. } \\
{ }^{6} \text { Gastric small cell cancer } 1 \text { year fol } \\
{ }^{7} \text { Unreliable data due to loss to follo } \\
{ }^{8} \text { Desmoid disease; metastatic liver } \\
\text { diabetes and vascular dementia. }\end{array}$ & $\begin{array}{l}\text { scopic sub } \\
\text { indicated. } \\
\text { cinoma did } \\
\text { my and diec } \\
\text { nly } \\
\text { vation follo } \\
\text { e after subt } \\
\text { ic intervent } \\
\text { of 20-mm } \\
\text { ciated with }\end{array}$ & $\begin{array}{l}\text { ction. } \\
\text { intervention a } \\
\text { c gastric cance } \\
\text { 30-mm proxin } \\
\text { my. } \\
\text { ESD of 18-mm } \\
\text { sepsis; gastro } \\
\text { nown origin; }\end{array}$ & $\begin{array}{l}\text { Iring follow-up; this p } \\
\text { fter surgery (recurre } \\
\text { on; pain requiring ov } \\
\text { bleed of unknown ori } \\
\text { ute on chronic kidney }\end{array}$ & $\begin{array}{l}\text { ent is not included } \\
\text { at scar); one patie } \\
\text { ight admission and }\end{array}$ & $\begin{array}{l}\text { table. } \\
\text { iderwent a repeat } \\
\text { ervation following }\end{array}$ \\
\hline
\end{tabular}


cobacter pylori status was available for 41 patients (39\%) at diagnosis of gastric adenoma (3 [7\%] positive and 38 [93\%] negative).

Five (three female) out of 104 patients (5\%) demonstrated HGD at primary diagnosis of the gastric adenoma ( $\vee$ Table 1 ), with a median polyp size of $25 \mathrm{~mm}$ (range 7-50 mm). All lesions containing HGD were resected endoscopically. Two patients had a recurrence following endoscopic mucosal resection (EMR); one underwent a repeat EMR and histology demonstrated LGD. The other underwent a subtotal gastrectomy, and postoperative histology revealed an unexpected adenocarcinoma (T4 N1); the patient died from recurrent gastric cancer 2 years later.

The risk of HGD on initial diagnosis was associated with adenoma size $(P=0.04)$ : median adenoma size was $25 \mathrm{~mm}$ in patients with HGD and $6 \mathrm{~mm}$ in patients with LGD. Gastric adenomas $>20 \mathrm{~mm}$ had a $33 \%$ risk of harboring HGD compared with 4 $\%$ in adenomas $\leq 20 \mathrm{~mm}(P=0.04)$. HGD was not associated with sex ( $6 \%$ female vs. $4 \%$ male; $P=0.30$ ) or location ( $8 \%$ proximal stomach vs. $3 \%$ distal; $P=0.17$ ) (Table 2 s).

A total of 98 patients (45 female) developed gastric adenomas demonstrating LGD at the index diagnosis of adenoma ( $\downarrow$ Table 1). Of these, 62 patients had adenomas located distal to the incisura, of which 37 demonstrated multiplicity; 32 patients had adenomas located in the proximal stomach of which 10 had multiple adenomas. Four lesions $>20$ mm were all located in the proximal stomach and all demonstrated multiplicity. A total of 58 patients (59\%) with lesions containing LGD underwent endoscopic therapy, as follows: 40 EMR, 4 endoscopic submucosal dissection (ESD), 2 argon plasma coagulation (APC), 1 ESD and knife-assisted EMR, 1 knife-assisted EMR, 9 snare polypectomy, and 1 cold biopsy (until removed).

Five patients were diagnosed with gastric carcinoma (median age 60 years, range $50-73$ years). Two were diagnosed with gastric carcinoma at the same time as index gastric adenoma diagnosis. During surveillance after intervention for gastric adenomas, gastric carcinoma was diagnosed in three patients (median time from initial diagnosis of gastric adenoma to cancer 66 months, range $66-115$ years) (Table $3 \mathrm{~s}$ ).

A total of 63 patients (61\%) underwent interventions for gastric adenomas ( $\triangleright$ Table 1 ) for lesions ranging from $1.5 \mathrm{~mm}$ to $50 \mathrm{~mm}$ (size of adenoma was not available for 42 patients [67\%]). Of these patients, 43 underwent EMR, 5 underwent ESD, and 15 had other interventions ( $\triangleright$ Table 1 ).

Complications occurred in three patients (5\%) who underwent endoscopic therapy, with one requiring reintervention for bleeding at the polypectomy site and two requiring unplanned overnight admission for analgesia and observation post-intervention. There were no cases of perforation following endoscopic therapy, no patient required surgical intervention, and there was no procedure-related mortality.

Two patients (3\%) developed an adenoma recurrence following endoscopic therapy. Both recurrences were in patients who had previously undergone EMR for proximal gastric adenomas measuring $30 \mathrm{~mm}$ and $50 \mathrm{~mm}$, respectively, where the index histology demonstrated focal HGD. One patient, aged 60 years, proceeded to surgery (subtotal gastrectomy) where his- tology confirmed the presence of adenocarcinoma (T4 N1); the patient died 2 years later from recurrence of gastric cancer. The other patient underwent further endoscopic therapy by EMR and is currently alive and free from cancer.

Of the 104 patients with known gastric adenomas, 8 died during follow-up, of whom 3 were diagnosed with metastatic gastric carcinoma: one had undergone previous EMR for gastric adenomas demonstrating LGD, another was diagnosed with HGD in their primary gastric adenoma, and one had a recurrence following a subtotal gastrectomy for an adenoma with HGD that was suspicious for malignancy. Five died from causes unrelated to gastric disease including desmoid disease, metastatic liver disease associated with a tumor of unknown origin, biliary sepsis, gastrointestinal bleed of unknown origin, and old age with multiple comorbidities. A total of 14 patients were lost to follow-up.

\section{Discussion}

By combining data from St. Mark's and Amsterdam UMC, we were able to evaluate the largest series of gastric adenomas in a FAP cohort to date. Gastric adenomas were present in $14 \%$ of patients with FAP, compared with $9 \%-50 \%$ in similar studies [17 - 19]. The studies showing higher incidence were from Asia and may reflect the higher background incidence of gastric disease in Asian populations. However, it is important to note that detection of proximal gastric adenomas can be challenging, particularly in the presence of gastric fundic gland polyposis. Given the historical nature of the data, along with advances in our understanding of gastric pathology and improvement in endoscopic systems, it is likely that the true incidence is higher than that observed in our study.

In the absence of standardized guidance, 63 patients (61\%) underwent excision or ablation for gastric adenomas. Of patients who did not undergo intervention based on histology from endoscopic biopsies, none developed gastric carcinoma. However endoscopic intervention did not eradicate cancer risk and three patients developed gastric carcinoma after gastric adenoma resection. Endoscopic resection is considered safe with a low rate of recurrence (3\%) and complications (5\%).

In current practice, an optical diagnosis of gastric adenoma is preferred and routine biopsy is avoided due to the risk of fibrosis, which may render definitive endoscopic therapy impossible. If feasible, direct resection is advised but in cases of diagnostic uncertainty, or if there is a suspicion of malignancy, biopsies can be taken. For large adenomas, a separate endoscopy session can be scheduled at a later date following appropriate informed consent. There are no optical diagnostic features validated for HGD but given that HGD was not observed in adenomas of $\leq 5 \mathrm{~mm}$, it would seem reasonable to use size of adenoma as an indication for endoscopic therapy. Our current approach for the management of gastric adenomas is shown in > Fig. 2.

Overall, $5 \%$ of gastric adenomas had HGD, which is consistent with previous studies [6, 17] and supports the concept that these adenomas are premalignant polyps that require intervention. Our analysis demonstrated a statistically significant 
Location of gastric adenoma
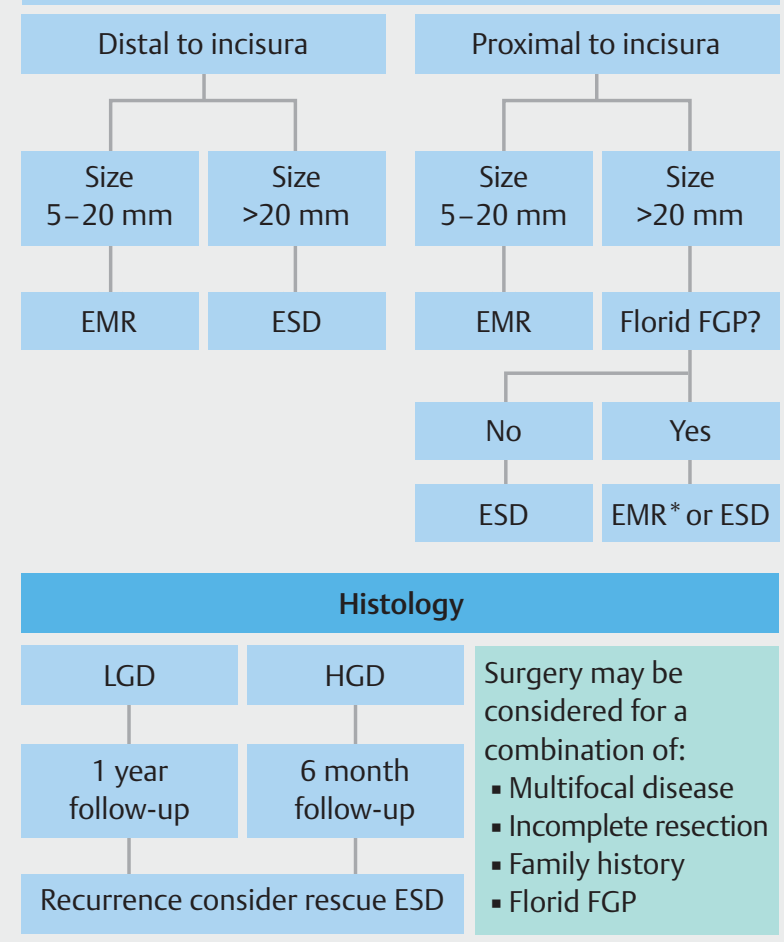

- Fig. 2 Current local protocol for management of gastric adenomas in patients with familial adenomatous polyposis. EMR, endoscopic mucosal resection; ESD, endoscopic submucosal dissection; EMR* ${ }^{*}$, knife-assisted EMR; FGP, fundic gland polyposis.

association between size of adenoma and $\operatorname{HGD}(P=0.04)$, where median adenoma size was $25 \mathrm{~mm}$ in patients with $\mathrm{HGD}$ compared with $6 \mathrm{~mm}$ in patients without HGD. This builds on the previous work by Walton et al. to demonstrate that adenomas with HGD tend to be larger in size $(7-50 \mathrm{~mm})[6]$.

Furthermore, a recent paper by Leone et al. reported that gastric cancers in patients with FAP was associated with solitary or "polypoid mound" polyps $>20 \mathrm{~mm}$ located in the proximal stomach [7]. Polyp size was available for 62 patients in our study, including four patients with HGD (three proximal and one distal). Our results show that the risk of HGD was $4 \%$ in any polyp $\leq 20 \mathrm{~mm}$ and $33 \%$ for gastric adenomas $>20 \mathrm{~mm}$ (no distal lesions $>20 \mathrm{~mm}$ were recorded). HGD was not associated with adenoma location $(P=0.17)$ or sex, despite a higher occurrence of HGD in females $(6 \%)$ than in males $(4 \% ; P=0.30)$. We acknowledge that these findings may be due to the relatively small numbers of HGD cases.

Our data show that gastric adenomas in patients with FAP may be more common in the distal stomach and may be more likely to be multiple. However, proximal gastric lesions may be more subtle and difficult to detect, especially in the presence of significant fundic gland polyposis, which are not located distally to the incisura. In our cohort, fundic gland polyposis was present at initial diagnosis of gastric adenoma in $83 \%$ of patients. This is not different from FAP patients in general [19] but may be the reason for the observed variation in distribution of gastric adenomas rather than a true predilection of gastric adenomas to occur in the distal stomach.

We recognize that our results may be limited by retrospective data collection. Furthermore, over the 30-year study period, advances in the quality of imaging and endoscopic technology, better understanding of the appearances of gastric pathology, and referral bias mean that we cannot accurately describe true incidence rates of gastric adenoma in this patient group.

Although the etiology of gastric adenomas in patients with FAP remains unclear, associations with desmoid disease [6], duodenogastric bile reflux [20], atrophic gastritis [18,21], and H. pylori [21] have been described in the literature. Studies have shown that the risk of gastric adenoma is higher in Korea and Japan $(15 \%-50 \%)[12,17,21,22]$ compared with Western populations $(2 \%-10 \%)[15,19,22]$ and there is no clear genotype-phenotype correlation so it is unclear why certain patients with FAP develop gastric adenomas. While we recognize the limitations of the study, it remains the largest cohort of FAP gastric adenomas to date and we suggest a new framework for the management of FAP gastric adenomas $>5 \mathrm{~mm}$ ( $\triangleright$ Fig. 2 ). The guidance is based on expert opinion with a view to conducting future studies to determine whether our proposed guidance reduces the incidence of gastric cancer in patients with FAP.

\section{Conclusion}

This is the largest series to date of gastric adenomas in patients with FAP. Overall, $14 \%$ of patients with FAP had gastric adenomas, of which $5 \%$ contained HGD. Endoscopic resection of gastric adenomas is safe with a low rate of recurrence; however, it does not completely eliminate the gastric cancer risk.

\section{Competing interests}

Prof. Dekker has received a research grant and equipment loans from FujiFilm. She has also received honoraria for consultancy work for FujiFilm, Olympus, Tillots, GI Supply, and CPP-FAP, and speaker fees from Olympus, Roche, and GI supply. All other authors declare that they have no conflicts of interest.

\section{References}

[1] Kinzler K, Nilbert M, Su L et al. Identification of FAP locus genes from chromosome 5q21. Science 1991; 253: 661-665

[2] Bisgaard M, Fenger K, Bulow S et al. Familial adenomatous polyposis (FAP): frequency, penetrance and mutation rate. Hum Mutat 1994; 3 : $121-125$

[3] Arvanitis M, Jagelman D. Mortality in patients with familial adenomatous polyposis. Dis Colon Rectum 1990; 33: 639-642

[4] Nugent KP, Spigelman AD, Phillips RKS. Life expectancy after colectomy and ileorectal anastomosis for familial adenomatous polyposis. Dis Colon Rectum 1993; 36: 1059-1062

[5] Ghorbanoghli Z, Bastiaansen BA], Langers AM] et al. Extracolonic cancer risk in Dutch patients with APC (adenomatous polyposis coli)associated polyposis. J Med Genet 2018; 55: 11-14 
[6] Walton S-J, Frayling IM, Clark SK et al. Gastric tumours in FAP. Fam Cancer 2017; 16: 363-369

[7] Leone P, Mankaney G, Sarvapelli S et al. Endoscopic and histologic features associated with gastric cancer in familial adenomatous polyposis. Gastrointest Endosc 2019; 89: 961-968

[8] Mankaney G, Leone P, Cruise M et al. Gastric cancer in FAP: a concerning rise in incidence. Fam Cancer 2017; 16: 371-376

[9] Jagelman DG, DeCosse JJ, Bussey HJ. Upper gastrointestinal cancer in familial adenomatous polyposis. Lancet 1988; 1: 1149-1151

[10] Iwama T, Mishima Y, Utsunomiya J. The impact of familial adenomatous polyposis on the tumorigenesis and mortality at the several organs. Its rational treatment. Ann Surg 1993; 217: 101-108

[11] Shibata C, Ogawa H, Miura K et al. Clinical characteristics of gastric cancer in patients with familial adenomatous polyposis. Tohoku J Exp Med 2013; 229: 143-146

[12] Park SY, Ryu JK, Park JH et al. Prevalence of gastric and duodenal polyps and risk factors for duodenal neoplasm in Korean patients with familial adenomatous polyposis. Gut Liver 2011; 5: 46-51

[13] Wood LD, Salaria SN, Cruise MW et al. Upper GI tract lesions in familial adnomatous polyposis (FAP). Am J Surg Pathol 2014; 38: 389-392

[14] Church JM, McGannon E, Hull-Boiner S et al. Gastroduodenal polyps in patients with familial adenomatous polyposis. Dis Colon Rectum 1992; 35: 1170-1173
[15] Sarre RG, Frost AG, Jagelman DG et al. Gastric and duodenal polyps in familial adenomatous polyposis: a prospective study of the nature and prevalence of upper gastrointestinal polyps. Gut 1987; 28: 306314

[16] Jagelman DG, Decosse JJ, Bussey HJR. Upper gastrointestinal cancer in familial adenomatous polyposis. Lancet 1988; 331: 1149-1151

[17] Lida M, Yao T, Itoh $\mathrm{H}$ et al. Natural history of gastric adenomas in patients with familial adenomatosis coli (Gardner's syndrome). Cancer 1988; 61: 605-611

[18] Ngamruengphong S, Boardman L, Heigh H et al. Gastric adenomas in familial adenomatous polyposis are common, but subtle, and have a benign course. Hered Cancer Clin Pract 2014; 12: 4

[19] Bianchi LK, Burke CA, Bennett AE et al. Fundic gland polyp dysplasia is common in familial adenomatous polyposis. Clin Gastroenterol Hepatol 2008; 6: 180-185

[20] Spigelman A, Granowska M, Phillips R. Duodeno-gastric reflux and gastric adenomas: a scintigraphic study in patients with familial adenomatous polyposis. J R Soc Med 1991; 84: 476-478

[21] Nakamura S, Matsumoto T, Kobori Y et al. Impact of Helicobacter pylori infection and mucosal atrophy on gastric lesions in patients with familial adenomatous polyposis. Gut 2002; 51: 485-489

[22] Yamaguchi $\mathrm{T}$, Ishida $\mathrm{H}$, Ueno $\mathrm{H}$ et al. Upper gastrointestinal tumours in Japanese familial adenomatous polyposis patients. Jpn J Clin Oncol 2016; 46: 310-315 